\title{
Association Between Different Risk Factors And Stroke At Emergency Department In Neuro Science Hospital
}

\author{
Muataz Fairooz Abd ${ }^{*}$, Basim Hanoon Jabbar ${ }^{*}$, Samer Mohammed Saeed Ridha ${ }^{*}$, Hayder Adnan Fawzi ${ }^{* *}$
}

\begin{abstract}
Background: Stroke is an acute neurologic injury and represents the $2^{\text {nd }}$ leading cause of mortality worldwide, and also the most leading cause of acquired disability and morbidity in adults.

Objective: Effect and association between stroke and risk factors.

Type of the study: A retrospective study.

Methods: The study conducted on 312 patients in 2016, all data were collected from patients' files from the emergency unit, which included basic demographic and disease characteristic, co morbid diseases, risk factors, final diagnosis.

Results: both previous stroke, ischemic heart disease was strong predictor of new stroke, and hypertension was major risk factor that associated with new stroke (odd ratio= 13.034, 2.659and 5.684respectively), no significant correlation between sex and stroke in the collected sample despite that female had slightly higher rate of stroke than male, patients with age above 70 years carry the highest risk to present with stroke.
\end{abstract}

Conclusion: The rate of stroke in Iraqi patients still significantly associated with advance age, two major predictor of stroke are associated with stroke previous stroke and ischemic heart disease and hypertension was the major risk factor correlated with new onset stroke, and prevention programs must be implemented on them especially hypertension since it is modifiable risk factor Key wards: Stroke, hypertension, risk factors

\section{Al-Kindy College Medical Journal 2017: Vol. 13 No.1 Page:128-131}

MBChB, FIBMS (neuro.), address: neuroscience hospital, Al-Rusafa health district

B* Pharm, R.Ph, address: Baghdad Teaching hospital, Medical city complex

Received 15 ${ }^{\text {th }}$ Feb 2017, accepted in final $30^{\text {th }}$ March 2017

Corresponding to :Muataz Fairooz Abd email: hayder.adnan2010@gmail.com, mobile: 07809794447, 07808347304
$\mathrm{S}$ troke is the acute neurologic injury that occurs as a result of either brain ischemia due to thrombosis, embolism, or systemic hypoperfusion orbrain hemorrhage due to intracerebral hemorrhage or subarachnoid hemorrhage, approximately 80 percent of strokes are due to ischemic cerebral infarction and 20 percent to brain hemorrhage ${ }^{[1]}$.Stroke representsthe $2^{\text {nd }}$ leading cause of mortality worldwide, and also the most leading cause of acquired disability and morbidityin adults inmost of the regions. Low and middle income countries represent the largest burden of stroke, which account for $>85 \%$ of stroke mortality worldwideand few reliable dataare available that can identify risk factors for stroke in most ofthese countries ${ }^{[2,3]}$. We aimed in this study to determine the frequency of different causesfor admission in our center, and determine the risk factor that associated with stroke and the correlation of vital signs with stroke.

Methods: This study was conduction in a tertiary hospital (NeuroscienceHospital/ Al-Rusafa)in which we retrospectively collected the data of 312 patients in November and December 2016 from our data records, the collected information included the demographic data, cause of admission, co-morbid disease, receiving wards, duration of arrival, fate of the patients and final diagnosis. Continuous variables presented using mean with standard deviation or median with its interquartile range, while discrete variables presented using number and their percentage. Chi square test used for discrete variables, while independent $t$ test or Mann Whitney $U$ test for continuous variables, binary logistic regression analysis used to determine the risk factors or predictors of stroke and the odd ratio was diagrammatically presented using forest plot, data was analyzed using SPSS 20.0 and GraphPad Prism 7.0 software packages.

Results :Patients received in the surgical wards in the emergency room (ER) unit had a median age of 26 years, while those received in the medical wards had a median age of 56 years;male to female ratio was 2:1 and $4: 1$ in medical and surgical wards respectively, the majority of the patients received from Baghdad residence as illustrated in table 1 . Patients with age group between 61 - 70 years represent the majority of received patients in our medical ER unit, the rest of the age group distribution illustrated in figure 1 . The mortality rate was $1.19 \%(95 \% \mathrm{Cl}=1.06-1.32 \%)$, about $27.0 \%$ of the patients was referred from other hospitals. Time of from insult to arrival at ER divided into: $44.4 \%$ had unknown time at presentation and $22.2 \%$ presented within 3 - 12 hours, $17.5 \%$ presented between $13-24$ hours the rest of the data are shown in table 2 . The major cause of admission was focal neurological deficit $39.7 \%$ followed by $19.0 \%$ as disturbed level of consciousness and $18.5 \%$ as seizures the rest of the 
data presented in table 3 . Hypertension represents the most common existing disease at presentation $38.1 \%$ followed by DM $20.6 \%$, previous stroke $19.8 \%$ the rest are shown in figure 2. Previous stroke, ischemic heart disease, represent the major predictors that had been associated with new onset stroke at presentation to medical ER, hypertension is the major risk factor for stroke development, on the other handhigher age at presentation, elevated blood pressure and elevated pulse rate also associated with new onset stroke at presentation as illustrated in table 4 and figure 3

\begin{tabular}{|c|c|c|c|}
\hline \multicolumn{3}{|c|}{$\begin{array}{r}\text { T a b l e 1: } \\
\text { Receiving medical wards }\end{array}$} & \multirow[t]{2}{*}{$P$ value } \\
\hline & Medical & Surgical & \\
\hline Age, median (IQR) & $56(32-65)$ & $26(3-45)$ & $<0.001$ \\
\hline \multicolumn{3}{|l|}{ Gender, n (\%) } & \multirow[t]{3}{*}{0.044} \\
\hline $\mathrm{Fem}$ a Ie & $84(33.3 \%)$ & $12(20 \%)$ & \\
\hline $\mathrm{M}$ a I e & $168(66.7 \%)$ & $48(80 \%)$ & \\
\hline \multicolumn{3}{|l|}{ Residency, n (\%) } & \multirow[t]{3}{*}{0.928} \\
\hline Baghdad & $236(93.7 \%)$ & $56(93.3 \%)$ & \\
\hline others & $16(6.3 \%)$ & $4(6.7 \%)$ & \\
\hline \multicolumn{4}{|c|}{ IQR: interquartile range ( $25 \%$ to $75 \%$ percentile) } \\
\hline
\end{tabular}

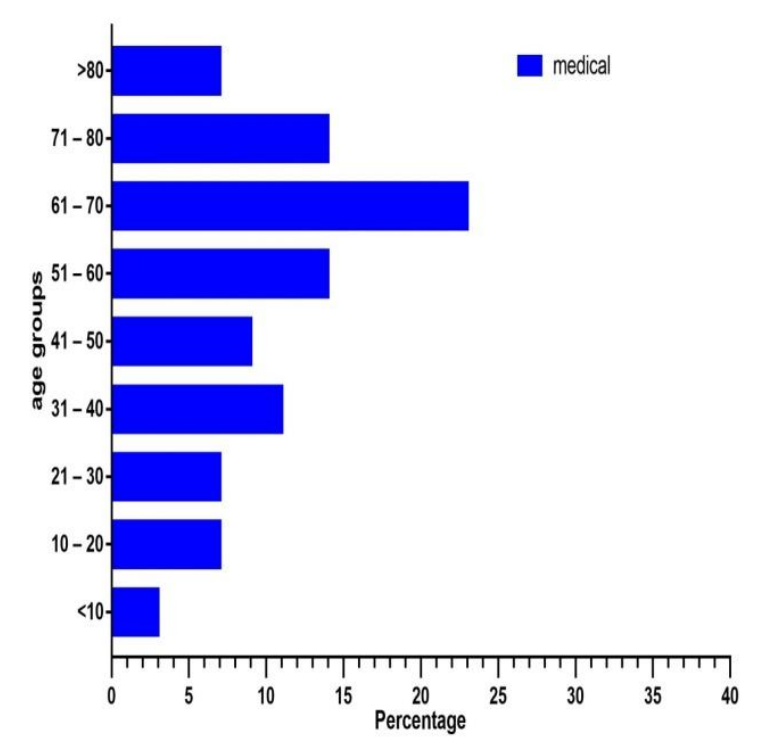

Figure 1: age groups in medical ER unit

\section{Table 2: source of referral,} duration of arival

and time at admission

\section{for the patients entering the medical ER}

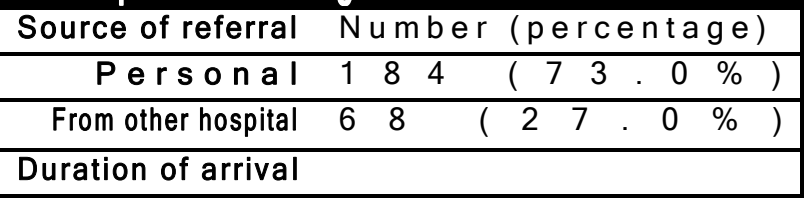

\begin{tabular}{|c|c|}
\hline Unknown & $\left(\begin{array}{lllll}4 & 4 & . & 4 & \%\end{array}\right)$ \\
\hline$h \circ u r s$ & $\left(\begin{array}{lllll} & 9 & . & 5 & \%\end{array}\right)$ \\
\hline $3-12$ hours & $\left(\begin{array}{llllll}2 & 2 & . & 2 & \%\end{array}\right)$ \\
\hline $13-24$ hours & $\left.\begin{array}{lllllll}( & 1 & 7 & . & 5 & \%\end{array}\right)$ \\
\hline $25-72$ hours & $\left(\begin{array}{lllll} & 6 & 3 & \%\end{array}\right)$ \\
\hline Time of admission & \\
\hline $8: 00$ AM - 3:00 PM & $\left(\begin{array}{llllll}7 & 4 & 6 & 6 & \%\end{array}\right)$ \\
\hline $3: 01$ PM - 7:59 AM & $\begin{array}{lll}4 \% \quad)\end{array}$ \\
\hline
\end{tabular}

Table 3: cause of admission in patients admitted to medical wards

Initial presentation Positive $\mathrm{N}$ e g a t i v e

\begin{tabular}{|llll}
\hline Focal neurological deficit & $100(39.7 \%)$ & $152(60.3 \%)$ \\
\hline
\end{tabular}

\begin{tabular}{|llllllll}
\hline D & L & O & C & $48(19.0 \%)$ & 204 & $(81.0 \%)$ \\
\hline
\end{tabular}

\begin{tabular}{|llllllll}
\hline B a c k & p a i n & $4(1.6 \%)$ & 248 & $(98.4 \%)$ \\
\hline
\end{tabular}

\begin{tabular}{|llll}
\hline Nausea and vomiting & $24(9.5 \%)$ & 228 & $(90.5 \%)$ \\
\hline
\end{tabular}

\begin{tabular}{|lllllllll}
\hline $\mathrm{F}$ & $\mathbf{e}$ & $\mathbf{v}$ & $\mathbf{e}$ & $\mathbf{r}$ & $20(7.9 \%)$ & 232 & $(92.1 \%)$ \\
\hline
\end{tabular}

\begin{tabular}{|lllllllllll|}
\hline $\mathbf{S}$ & $\mathbf{e}$ & $\mathbf{i}$ & $\mathbf{z}$ & $\mathbf{u}$ & $\mathbf{r}$ & $\mathbf{e}$ & $44(18.5 \%)$ & 208 & $(82.5 \%)$ \\
\hline S & & & O & & & B & $16(6.3 \%)$ & 236 & $(93.7 \%)$ \\
\hline
\end{tabular}

\begin{tabular}{llll}
\hline P s y chiatric & $8(3.2 \%)$ & $244(96.8 \%)$ \\
\hline
\end{tabular}

\section{9}

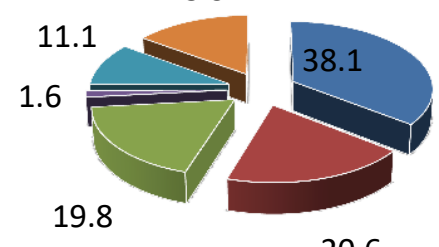

- Hypertension

$$
20.6
$$

$$
\begin{aligned}
& \text { Diabetic } \\
& \text { mellitus } \\
& \text { previous } \\
& \text { Stroke } \\
& \text { Cancer }
\end{aligned}
$$

\begin{tabular}{|c|c|c|c|c|c|}
\hline \multirow[t]{2}{*}{ Risk factors } & $S t r$ & o $\mathrm{k} \mathrm{e}$ & OR & $95 \% \mathrm{Cl}$ & Pvalue \\
\hline & Negative & Positive & & & \\
\hline Hypertension & $44(28.9 \%)$ & $52(52.0 \%)$ & 2.659 & $1.571-4.500$ & $<0.001$ \\
\hline$M$ & $28(18.4 \%)$ & $24(24.0 \%)$ & 1.398 & $0.756-2.588$ & 0.285 \\
\hline Previous stroke & $8(5.3 \%)$ & $42(42.0 \%)$ & 13.034 & $5.768-29.543$ & $<0.001$ \\
\hline Epilepsy & $24(15.8 \%)$ & $4(4.0 \%)$ & 0.222 & $0.075-0.662$ & 0.007 \\
\hline $\begin{array}{ll}\mathrm{I} \\
\mathrm{H}\end{array}$ & $8(5.3 \%)$ & $24(24.0 \%)$ & 5.684 & $2.437-13.260$ & $<0.001$ \\
\hline Age at presentation & $39.5 \pm 20.0$ & $66.4 \pm 13.1$ & 1.106 & $1.076-1.136$ & $<0.001$ \\
\hline $\mathrm{V}$ & $a$ & & & $\mathrm{~g}$ & s \\
\hline S B & $123.2 \pm 23.4$ & $139.2 \pm 30.0$ & 1.027 & $1.015-1.039$ & $<0.001$ \\
\hline D $\quad$ B & $77.9 \pm 15.4$ & $85.0 \pm 13.3$ & 1.036 & $1.016-1.057$ & $<0.001$ \\
\hline $\mathrm{P}$ & $81.6 \pm 16.9$ & $89.5 \pm 16.3$ & 1.031 & $1.013-1.049$ & 0.001 \\
\hline $\mathbf{R}$ & $22.5 \pm 15.1$ & $21.4 \pm 5.3$ & 0.992 & $0.968-1.015$ & 0.486 \\
\hline Temperature & $37.1 \pm 1.3$ & $37.1 \pm 0.3$ & 1.046 & $0.808-1.355$ & $\overline{0.734}$ \\
\hline $\mathrm{S} \quad \mathrm{P} \quad \mathrm{O}_{2}$ & $92.5 \pm 13.0$ & $94.1 \pm 5.1$ & 1.016 & $0.988-1.046$ & $\overline{0.271}$ \\
\hline
\end{tabular}

Figure 2: percentage of co morbid disease admitted in medical ward 


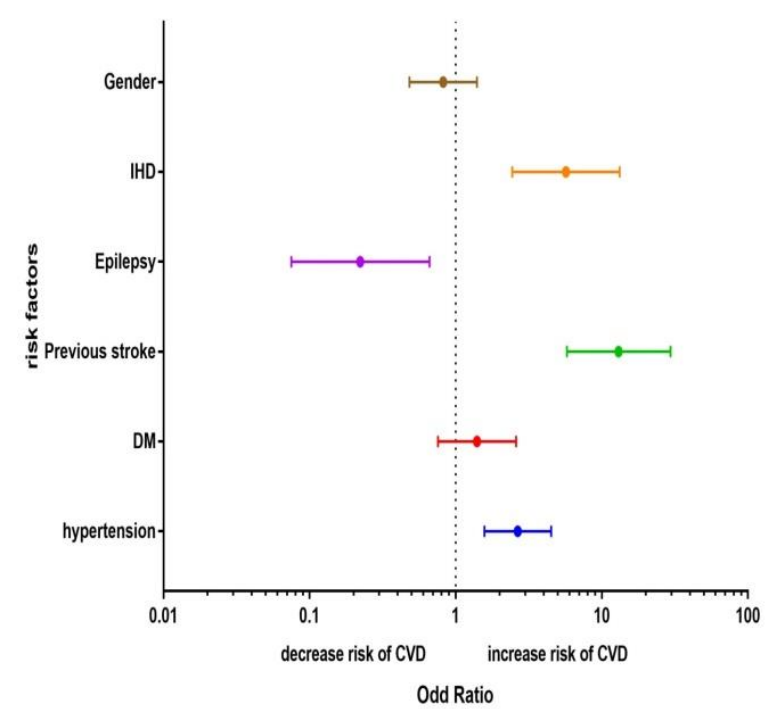

Figure 3: Forest plot of risk factors and predictors for CVD

\begin{tabular}{|c|c|c|c|}
\hline Age group (years) & $\mathrm{O}$ & $95 \%$ C । & $\mathrm{P} v \mathrm{a} \mid \mathrm{u} e$ \\
\hline $30-40$ & 0.042 & $0.009-0.191$ & $<\begin{array}{lllll} & 0 & 0 & 0 & 1\end{array}$ \\
\hline $41-50$ & 0.050 & $0.011-0.232$ & $<0.0001$ \\
\hline $51-60$ & 0.077 & $0.019-0.275$ & $<0.001$ \\
\hline $61-70$ & 375 & $0.112-1.259$ & 0.112 \\
\hline $71-80$ & 2.0000 & $0.422-9.056$ & 0.368 \\
\hline$>80$ & $\mathrm{R} \quad \mathrm{e}$ & e r & $\mathrm{n}$ \\
\hline
\end{tabular}

Discussion:This study show that previous stroke, hypertension and ischemic heart disease account for most of the risks for new onset stroke presented to our center (tertiary referring specialized center), our study provide essential information about the most common causes of stroke which will be the bases of larger cohort study that will follow. The results of this study showthat hypertension representsone of the higher highest risk factor correlated with stroke with an odd ratio of 2.659 (95\% Cl: $1.571-4.5)$, this outcome is similar to others; O'Donnell et al ${ }^{[4]}$ reported that history hypertension was the highest risk factor associate with all cause of stroke (odd ratio $=2.64,99 \% \mathrm{Cl}: 2.26-3.08$ ) and this account for $24.6 \%$ of population attribute risk of stroke their findings is similar to ours, Carrera et al also reported similar outcome of significant association between stoke and hypertension ${ }^{[5]}$. In addition to using the history of blood pressure as risk factor for stroke, we included vital signs at presentation in the analysis and we found both elevated systolic and diastolic blood associated with new onset stroke (despite the majority of had antihypertension medication indicating possibly improper use of their medication or non-compliance with them as potentially source of this significant association of stroke with hypertension), this focusing onblood pressure as major risk factor will be reflected as major target for intervention since it is the most amenable to change in primary care setting and easily screening programs for prevention which need modest equipment and litter specialized expertise ${ }^{[4]}$. In our study patients with age group 71 - 80 years had the highest risk for developing stroke this risk was statistically not significant compared to more than 80 years and 61 - 70 years groups, for 50 s, 40 , and 30 s decade the risk of stroke was significantly lower than above 60 years groups in descending pattern, Brett et al ${ }^{[6]}$ reported in a population based study on stroke a mean age of 69.2 years in 2005 which represent a decline in mean age compared to 1993/1994 cohort of mean 71.2 years they found increase in the proportion of $<50$ years having stroke in recent years, in our study peak stroke presented at 70 s decade and no significant difference compared to $60 \mathrm{~s}$ decade indicating we still have extreme age as strong risk factor for new onset stroke, which can be attribute to longer duration of smoking, hypertension, obesity and other risk factors for developing stroke ${ }^{[6]}$.

Concerning vital signs elevated blood pressure and pulse rate associated significantly with stroke, our findings of blood pressure can be attribution to the chronic hypertension, this process in acute setting often represents an appropriate response to maintain brain perfusion.

In our study we did not found a significant difference in the sex distribution as risk factor for stroke $(\mathrm{OR}=0.821$, $95 \% \mathrm{Cl}: 0.482$ - 1.398), despite this non-significant difference still slightly female had high rate of stroke $42.9 \%$ compared to male $38.1 \%$, this is similar to previous study ${ }^{[7]}$ in which the authors reported a higher risk of stroke for female, and they account this difference to sex steroid hormones, particularly oestrogen and supported by robust sex differences in animal models of ischaemic stroke. ${ }^{[8]}$ Oestradiol has very potent effects on endothelia that promote dilation and blood flow, whereas testosterone has the opposite effects. ${ }^{[9]}$ Similarly, cerebrovascular reactivity is the most robust in premenopausal women, but postmenopausal women have poorer responses than age-matched men. Postmenopausal women receiving oestrogen replacement therapy have reactivity responses similar to premenopausal women. ${ }^{[10]}$ In addition to vascular effects, oestrogen has anti-inflammatory effects that might be modulated by antioxidant and antiapoptosis effects. ${ }^{[11]}$ All of these findings suggest that women are protected by endogenous oestrogens. As a putative neuroprotective agent, oestradiol might be the most widely studied molecule, and yet it has never been tested in patients with acute stroke. ${ }^{[12]}$

Conclusion: The rate of stroke in Iraqi patients still significantly associated with advance age, three major risk factor are associated with stroke previous stroke, hypertension and ischemic heart disease, and prevention programs must be implemented on them especially hypertension since it is modifiable risk factor 


\section{References}

[1] Caplan LR. Basic pathology, anatomy, and pathophysiology of stroke. In: Caplan's Stroke: A Clinical Approach, $4^{\text {th }}$ ed, Saunders Elsevier, Philadelphia 2009. p.22.

[2] Feigin VL. Stroke in developing countries: can the epidemic be stopped and outcomes improved? Lancet Neurol 2007; 6: 94-97.

[3] Strong K, Mathers C, Bonita R. Preventing stroke: saving lives around the world. Lancet Neurol 2007; 6: 182-87.

[4] O'Donnell MJ, Xavier D, Liu L, Zhang H, Chin SL, Rao-Melacini $\mathrm{P}$, et al. Risk factors for ischaemic and intracerebral haemorrhagic stroke in 22 countries (the INTERSTROKE study): a case-control study. Lancet. 2010;376:112-123

[5]Carrera E. Maeder-Ingvar M.Rossetti A.O.Devuyst G.Bogousslavsky J. Trends in Risk Factors, Patterns and Causes in Hospitalized Strokes over 25 Years: The Lausanne Stroke Registry. Cerebrovasc Dis 2007;24:97103. (DOI:10.1159/000103123)

[6] Kissela BM, Khoury JC, Alwell K, Moomaw CJ, Woo D, Adeoye O, Flaherty ML, Khatri P, Ferioli S, De Los Rios La Rosa F, Broderick JP, Kleindorfer DO. Age at stroke: temporal trends in stroke incidence in a large, biracial population. Neurology. 2012;79:1781-1787.
[7]Mathew J Reeves, Cheryl D Bushnell, George Howard, et al. Sex differences in stroke: epidemiology, clinical presentation, medical care, and outcomes. The Lancet Neurology, Volume 7, Issue 10, October 2008, Page 859.

[8]Postischemic estrogen reduces hypoperfusion and secondary ischemia after experimental stroke McCullough LD, Alkayed NJ, Traystman RJ, Williams MJ, Hurn PD Stroke. 2001 Mar; 32(3):796-802.

[9] Influence of sex steroid hormones on cerebrovascular function. Krause DN, Duckles SP, Pelligrino DA J AppIPhysiol (1985). 2006 Oct; 101(4):1252-61.

[10] Age and sex differences in cerebral hemodynamics: a transcranial Doppler study. Matteis M, Troisi E, Monaldo BC, Caltagirone C, Silvestrini M Stroke. 1998 May; 29(5):963-7.

[11]Estrogen and ischemic neuroprotection: an integrated view. McCullough LD, Hurn PD Trends EndocrinolMetab. 2003 Jul; 14(5):228-35.

[12] Bushnell CD, Hurn P, Colton C, et al. Advancing the study of stroke in women: summary and recommendations for future research from an NINDSSponsored Multidisciplinary Working Group.Stroke. 2006 Sep; 37(9):2387-99. 